\title{
Formulation and Characterization of Chitosan Microparticulate System Using Central Composite Design for the Drug: Lafutidine
}

\author{
Sunil Kumar ${ }^{1,2, \star}$, Naveen Goyal ${ }^{3}$ \\ ${ }^{1}$ Research Scholar, Uttarakhand Technical University, Dehradun, Uttarakhand, INDIA. \\ ${ }^{2}$ Assistant Professor, Vaish Institute of Pharmaceutical Education and Research, Rohtak, Haryana, INDIA. \\ ${ }^{3}$ Deputy Registrar, Gurugram University, Gurugram, Haryana, INDIA.
}

\begin{abstract}
Aim: To formulate a Micro particulate system using central composite design to remain in the stomach for prolonged time and used for Gastroretentive drug delivery. Materials and Methods: Gastroretentive Microspheres were prepared by Emulsion Solvent Evaporation. Micro particulate system were evaluated for micro meritic study, percentage yield, drug entrapment efficiency, in-vitro buoyancy, surface morphology, in-vitro drug release, in-vivo floating study and stability studies. Results: The micro meritic parameters of floating microspheres were found to be within the acceptable limits. The particle size of microspheres was found to be in the range $3.43-15.38 \mu \mathrm{m}$. The entrapment efficiency was found to be in the range of $72.02-95.02 \%$. The floating microspheres were spherical in shape with distinct pores, slightly rough surface when observed under scanning electron microscopy. The percentage yield was found to be in the range of $68-89 \%$. The in-vitro buoyancy was found to be in the range of $55.67-92.55 \%$ and a total buoyancy time of more than $10 \mathrm{~h}$. The in-vitro dissolution studies showed a cumulative \% release in the range of 77.67-95.41\%. The optimized formulation F4 was floating in rat stomach for almost $8 \mathrm{~h}$. All the formulations followed Korsemeyer- Peppas kinetics indicating drug release by non-fickian release mechanism. The stability studies showed that floating microspheres were stable at $40 \pm 2{ }^{\circ} \mathrm{C}$. Conclusion: The optimized formulation showed good floating for $12 \mathrm{~h}$ in stomach of rat. The formulation was able to treat the alcohol induced ulcer and also found good stability.
\end{abstract}

Key words: Lafutidine, Chitosan, Central composite design, In vitro drug release, Microparticulate system.

\section{INTRODUCTION}

The most common and suitable route for various drugs is oral route. This route usually considered as perfect drug delivery system because of these two main properties:

- Prolonged action with a single dose.

- Directly deliver the drug to the target. ${ }^{1}$

\section{Floating drug delivery systems (FDDS)}

Floating systems are low-density systems that have sufficiently buoyancy to float over the gastric content and remain buoyant in the stomach without affecting gastric emptying rate for a prolonged period of time, which results in a increased gastric retention time and a better control of fluctuation in plasma drug concentration. After release of drug, the residual system is emptied from the stomach. ${ }^{2}$ These problems have prompted researchers to design a drug delivery system which can stay in the stomach for prolonged and predictable period. ${ }^{3}$ Attempts are being made to develop a drug delivery system which can provide therapeutically effective plasma drug concentration for a longer period, thereby reducing the dosing frequency and minimizing fluctuation in plasma drug concentration at steady state by delivering the drug in a controlled and
Submission Date: 11-05-2020; Revision Date: 02-12-2020; Accepted Date: 01-03-2021

DOI: 10.5530/ijper.55.2.73 Correspondence: Mr. Sunil Kumar Research Scholar, Uttarakhand Technical University, Dehradun, Uttarakhand, INDIA. Assistant Professor, Vaish Institute of Pharmaceutical Education and Research, Rohtak, Haryana, INDIA. Phone no: +91-01262248485

Email id: sunil.pharmacist@ yahoo.co.in

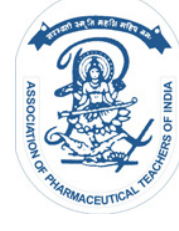

www.ijper.org 
reproducible manner. ${ }^{4,5}$ Lafutidine is newly developed second generation histamine H2-receptor antagonist, having poor water solubility and short elimination half-life up to $3.0 \mathrm{hr}$, belonging to BCS class-II drugs. This drug is very much effective in the treatment of gastric ulcer, gastroesophageal reflux disease and pathological hyper secretory conditions. The drug has plasma half- life range from $1.92 \mathrm{hr}$ and it is given orally at a dose of $10-20 \mathrm{mg}$, two or three times a day. Chitosan (obtained by alkaline deacetylation of chitin) is a swellable, natural linear bio poly amino saccharide. Chitin is a straight homopolymer composed of -(1,4)-linked N-acetylglucosamine units, while chitosan comprises of copolymers of glucosamine and N-acetylglucosamine. ${ }^{6,7}$

Advantages of chitosan:

- It forms film that reduces effect of gastrointestinal transit time.

- Hallow microcapsule tend to float on gastric fluid for about $12 \mathrm{hrs}$.

- Release rate of drug followed zero order kinetics

\section{MATERIALS AND METHODS}

Drug (Lafutidine) has been obtained as a gift sample from Unichem Lab. and other excipients has been procured/purchased.

Identification of Formulation Variables and Responses: Fabrication of GRDF with Chitosan The formulation variables were selected as (a) Drug: Chitosan ratio (b) Chitosan: Gelling agent ratio at three levels $-1,0$ and +1 .

The responses selected for this formulation will be (a) Particles size, (b) drug entrapment efficiency, (c) In-vitro buoyancy studies, (d) Dissolution studies.

A total of 13 formulations for 2 factors and 3 levels central composite design as generated by design expert will be prepared (Batches CF1 to CF13) as given in Table 1.

\section{Determination of $\lambda_{\max }$}

- $10 \mathrm{mg}$ of Lafutidine was weighed and transferred into a $10 \mathrm{~mL}$ of volumetric flask containing approximately $5 \mathrm{~mL}$ of acetic acid. Flask was then gently shaken and volume was finally made up to 10 $\mathrm{mL}$ using $0.1 \mathrm{~N} \mathrm{HCl}$.

- $1 \mathrm{~mL}$ of this solution was pipette out in another volumetric flask and volume was made up to $10 \mathrm{~mL}$ $(100 \mu \mathrm{g} / \mathrm{mL}) .1 \mathrm{~mL}$ of this solution was pipette out in another volumetric flask and volume was made up to $10 \mathrm{~mL}(10 \mu \mathrm{g} / \mathrm{mL})$ and absorbance was measured from $200 \mathrm{~nm}$ to $400 \mathrm{~nm}$ for determination of $\lambda_{\max }$ of Lafutidine by using UV spectrophotometer.

- Same procedure was repeated for phosphate buffer (pH 6.8) and distilled water.

- The peaks were observed at $286 \mathrm{~nm}$ in $0.1 \mathrm{~N} \mathrm{HCl}$, at $285 \mathrm{~nm}$ in phosphate buffer $(\mathrm{pH}$ 6.8) and at 276.5 $\mathrm{nm}$ in distilled water.

\section{Establishment of Calibration Plot}

- $10 \mathrm{mg}$ of Lafutidine was accurately weighed and transferred into a $10 \mathrm{~mL}$ volumetric flask containing approximately $5 \mathrm{~mL}$ of acetic acid. Flask was then gently shaken and volume was finally made up to $10 \mathrm{~mL}$ using the same solvent (stock solution " $\mathrm{A}$ ")

- $1 \mathrm{~mL}$ of this solution was pipette out in another volumetric flask and volume was made up to 10 $\mathrm{mL}$ with $0.1 \mathrm{~N} \mathrm{HCl}$ in order to obtain the resulting solution of $100 \mu \mathrm{g} / \mathrm{mL}$ (stock solution "B"). Finally by using stock solution "B", solutions of various concentrations such as $2,4,6,8,10 \mu \mathrm{g} /$ $\mathrm{mL}$ were prepared. $0.1 \mathrm{~N} \mathrm{HCl}$ was taken as blank and absorbance of different dilutions were taken at $286 \mathrm{~nm}$. The readings for the calibration curve are shown in Table 2 (within 0.1 N HCL), Table 3 (within phosphate buffer), Table 4 (within distilled water) and plots are shown in Figure 1 (with 0.1 N HCL), Figure 2 (within phosphate buffer) and Figure 3 (within distilled water).

Table 1: Coded factor levels of the formulation.

\begin{tabular}{|c|c|c|c|}
\hline Formulation Code & \multicolumn{3}{|c|}{ Coded Factor Levels } \\
\hline Sr. No. & \multicolumn{2}{|l|}{$\mathbf{x}$} & $\mathbf{x}$ \\
\hline CF1 & \multicolumn{2}{|l|}{$-1^{1}$} & $-1^{2}$ \\
\hline CF2 & \multicolumn{2}{|l|}{-1} & 0 \\
\hline CF3 & \multicolumn{2}{|l|}{-1} & +1 \\
\hline CF4 & \multicolumn{2}{|l|}{0} & -1 \\
\hline CF5 & \multicolumn{2}{|l|}{0} & 0 \\
\hline CF6 & \multicolumn{2}{|l|}{0} & +1 \\
\hline CF7 & \multicolumn{2}{|c|}{+1} & -1 \\
\hline CF8 & \multicolumn{2}{|c|}{+1} & 0 \\
\hline CF9 & \multicolumn{2}{|c|}{+1} & +1 \\
\hline CF10 & \multicolumn{2}{|l|}{0} & 0 \\
\hline CF11 & \multicolumn{2}{|l|}{0} & 0 \\
\hline CF12 & \multicolumn{2}{|l|}{0} & 0 \\
\hline CF13 & \multicolumn{2}{|l|}{0} & 0 \\
\hline \multicolumn{4}{|c|}{ Translation of coded levels in actual units } \\
\hline Coded level & -1 (low) & 0 (middle) & +1(high) \\
\hline $\begin{array}{l}\mathrm{X} \text { : Drug Chitosan } \\
\text { Ratio }\end{array}$ & $1: 1$ & $1 ; 2$ & $1: 3$ \\
\hline $\begin{array}{l}\text { X : Chitosan: } \\
\text { Gelling Agent } \\
\text { (TPP) Ratio }\end{array}$ & $1: 3$ & $1: 4$ & $1: 5$ \\
\hline
\end{tabular}


- Similarly, standard plots of pure Lafutidine were also constructed using phosphate buffer $(\mathrm{pH}$ 6.8) at $285 \mathrm{~nm}$ and distilled water at $276.5 \mathrm{~nm}$.

Preparation of Microsphere with Chitosan: Gastroretentive Microspheres were prepared by Ionotropic Gelation Technique. Accurately weighed amount of drug (Table 5) was dispersed uniformly in $2 \%$ Acetic acid with stirring. To this dispersion, desired polymer (Chitosan) in different concentrations was mixed in suitable proportion and stirring is continued. The resulting solution was then added drop by drop into Light Liquid Paraffin containing suitable concentration of Span 60 and Magnesium Sterate. Then the solution was kept on Magnetic stirrer for 1 $\mathrm{hr}$ for the emulsification. Then Gelling agent (Sodium Triployphosphate) dissolves in water and added to the above prepared Emulsion. The solution was kept on Magnetic stirrer for 3 to 4 hr at 60 to 65' C. The formed microspheres were kept suspended in the solution for 1 day to improve their mechanical strength and then collected, washed with Petroleum ether. The formulated microspheres (Batch CF1-CF13) were then dried using vacuum oven at $40-45^{\circ} \mathrm{C}$ and stored in airtight containers.

\section{RESULTS AND DISCUSSION}

The microsphere blend was estimated for their flow properties. Bulk density and Tapped density were found

\begin{tabular}{|c|c|c|}
\hline \multicolumn{3}{|c|}{ Table 2: Calibration Plot of drug in 0.1 N HCL. } \\
\hline Sr. No. & Conc. $(\boldsymbol{\mu g} / \mathbf{m L})$ & Absorbance \\
\hline 1 & 2 & 0.1301 \\
\hline 2 & 4 & 0.2512 \\
\hline 3 & 6 & 0.3814 \\
\hline 4 & 8 & 0.5132 \\
\hline 5 & 10 & 0.6312 \\
\hline
\end{tabular}

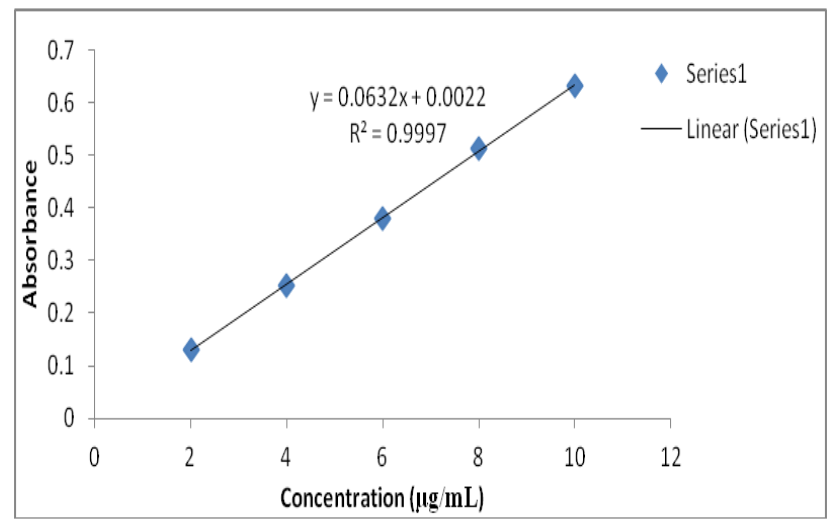

Figure 1: Calibration Plot of drug in $0.1 \mathrm{~N} \mathrm{HCL}$. between $0.515-0.580 \mathrm{gm} / \mathrm{cm}^{3}$ and $0.571-0.651 \mathrm{gm} /$ $\mathrm{cm}^{3}$ respectively. Results are shown in Table 2. Carr's index indicating good flow, was found to be in the range of 5.21-14.73. Hausner's ratio values indicating low interparticle friction for all the formulations were found to be near about 1.1. Angle of repose was found between 20.07-26.80. These values indicate the prepared blend exhibited good flow properties. The drug was confirmed by DSC analysis and there was a sharp peak at $102.67^{\circ} \mathrm{C}$ corresponding to its melting point. The absence of interaction between physical mixtures was further confirmed by DSC analysis. The IR spectra of Lafutidine showed -1 characteristics peaks at $3278 \mathrm{~cm}$ due to -NH Stretch, 3094-2940 cm due to C-H Stretch, at $1620 \mathrm{~cm}$ due to $\mathrm{C}=\mathrm{C}$ Stretch, $1261 \mathrm{~cm}$ at due to N-C Bending, $1211-1157 \mathrm{~cm}$ due to C-O stretching, 1211 $1157 \mathrm{~cm}$ at due to $\mathrm{C}-\mathrm{O}$ Bending.

Micromeritics Studies of Prepared Microspheres: Following micromeritics parameters has been carried out.

a. Angle of repose: This is the angle between the horizontal plane and surface of a pile of microspheres blend. It was determined by using the funnel method. The perfectly weighed granule blend is being taken in the funnel. ${ }^{7}$ The altitude of the funnel adjusted to the maximum cone height $(\mathrm{h})$ and microspheresblend was poured through the funnel freely on to the surface. Then the radius of the heap ( $r$ ) was measured and

\begin{tabular}{|c|c|c|}
\multicolumn{3}{|c|}{ Table 3: Calibration Plot in Phosphate Buffer (pH } \\
\hline \multicolumn{3}{|c|}{ ). } \\
\hline Sr. No. & Conc. $(\boldsymbol{\mu g} / \mathrm{mL})$ & Absorbance \\
\hline 1 & 2 & 0.1101 \\
\hline 2 & 4 & 0.2311 \\
\hline 3 & 6 & 0.3441 \\
\hline 4 & 8 & 0.4322 \\
\hline 5 & 10 & 0.5330 \\
\hline
\end{tabular}

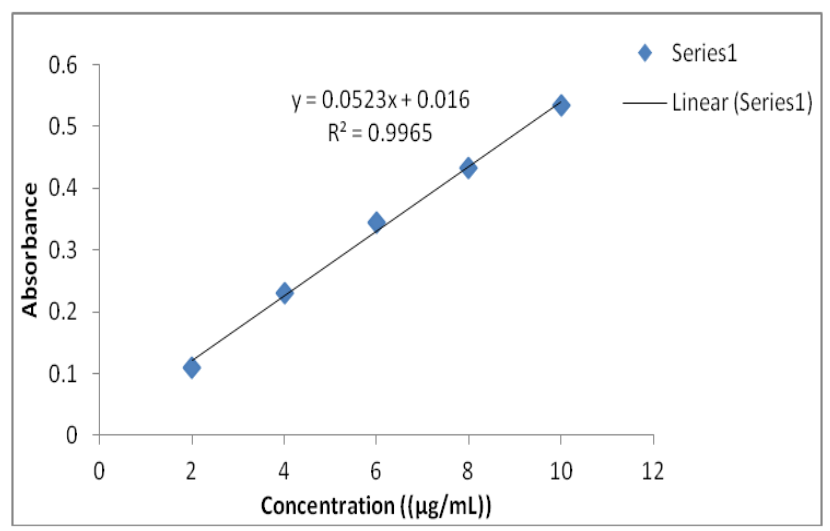

Figure 2: Calibration Plot of drug in Phosphate Buffer (pH 6.8). 
angle of repose was calculated. The diameter of the microspheres cone will be measured and then the angle of repose. ${ }^{8,9}$

\section{$\tan \theta=h / r$}

b. Bulk density (BD) and Tapped density (TD):2 $\mathrm{g}$ of granules blend was introduced to a measuring cylinder of $100 \mathrm{ml}$. The cylinder was tapped 100 times and the tapped volume of packing was recorded. ${ }^{10,11}$

$\mathrm{BD}$ and $\mathrm{TB}$ are calculated using the following formulae:

$\mathrm{BD}=\frac{\text { weight of the granule blend }}{\text { Untapped volume of the granules }}$

TD weight of the granule blend

tapped volume of the granules

c. Compressibility index: It was calculated by using the Carr's compressibility index as given in formula below here. ${ }^{12,13}$

Carr's Index $=\frac{(\mathrm{TD}-\mathrm{BD}) \times 100}{\mathrm{TD}}$

Where, TD is tapped density and BD is bulk density.

d. Hausner's ratio: It is an index of ease of powder flow; calculated using the following formula. ${ }^{14,15}$

hausner's Ratio $=\frac{\mathrm{TD}}{\mathrm{BD}}$

Where, TD is tapped density and BD is bulk density.

All these calculated flow properties of different batch are given in Table 6. From the above pre compression

\begin{tabular}{|c|c|c|}
\hline \multicolumn{2}{|c|}{ Table 4: Calibration Plot in Distilled Water. } \\
\hline Sr. No. & $\begin{array}{c}\text { Conc. } \\
(\mu \mathrm{g} / \mathrm{mL})\end{array}$ & Absorbance \\
\hline 1 & 2 & 0.1291 \\
\hline 2 & 4 & 0.2412 \\
\hline 3 & 6 & 0.3842 \\
\hline 4 & 8 & 0.5121 \\
\hline 5 & 10 & 0.6333 \\
\hline
\end{tabular}

results it was found that the granular blend has good flow.

SEM: The microscopy image of the optimized formulation is shown in Figure 4. The prepared microspheres were spherical in shape with slight distinct pores of the slightly rough surface of microspheres. Yellow squares represent the presence of microspheres. The samples for SEM were prepared by adhering the microparticleon a double adhesive tape stuck to an aluminum stub. The stubs were then coated with

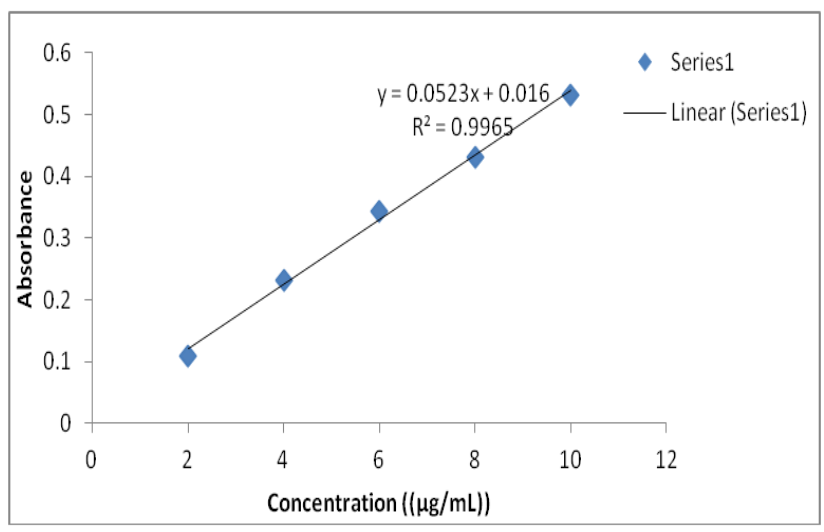

Figure 3: Calibration Plot of drug in Distilled Water.

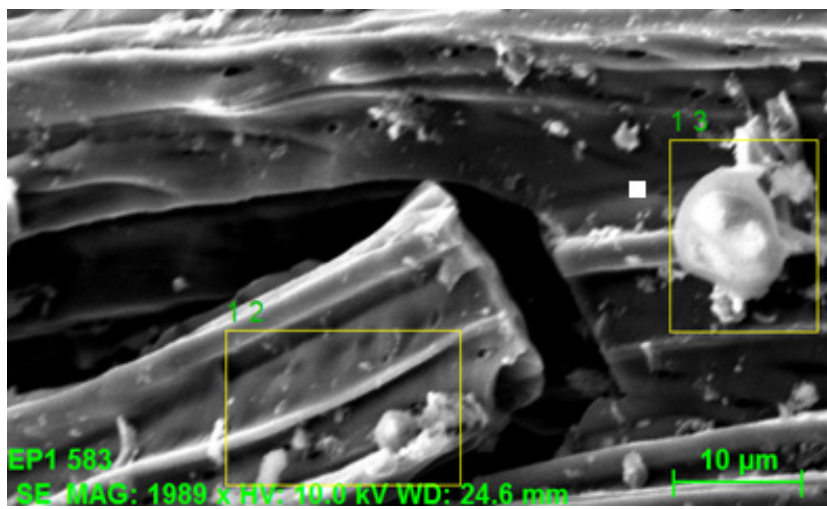

Figure 4: Scanning electron micrographs of floating microspheres.

\begin{tabular}{|c|c|c|c|c|c|c|c|c|c|c|c|c|c|}
\hline INGREDIENTS & CFI & CF2 & $\mathrm{CF} 3$ & CF4 & CF5 & CF6 & CF7 & CF8 & CF9 & CF10 & CF11 & CF12 & CF13 \\
\hline Lafutidine & 500 & 500 & 500 & 500 & 500 & 500 & 500 & 500 & 500 & 500 & 500 & 500 & 500 \\
\hline Span 60 & 750 & 750 & 750 & 750 & 750 & 750 & 750 & 750 & 750 & 750 & 750 & 750 & 750 \\
\hline Mag. Sterate & 750 & 750 & 750 & 750 & 750 & 750 & 750 & 750 & 750 & 750 & 750 & 750 & 750 \\
\hline Chitosan & 125 & 100 & 83.33 & 250 & 200 & 166.66 & 375 & 300 & 250 & 200 & 200 & 200 & 200 \\
\hline Sodium TPP & 375 & 400 & 416.66 & 750 & 800 & 833.33 & 1125 & 1200 & 1250 & 800 & 800 & 800 & 800 \\
\hline $\begin{array}{c}\text { Sodium } \\
\text { Bicarbonate }\end{array}$ & 500 & 500 & 500 & 500 & 500 & 500 & 500 & 500 & 500 & 500 & 500 & 500 & 500 \\
\hline
\end{tabular}


silver under an argon atmosphere using a high-vacuum evaporator (Polaron SEM coating system). The internal cavity of the microparticle was examined by cutting into two sections diametrically with a sharp surgical steel blade. The coated sample was then randomly scanned and photomicrographs were taken with a scanning electron microscope (EVO-50, ZEISS; UK).

Fourier transform infrared (FTIR) spectroscopy: FTIR spectroscopy was carried out to study the compatibility of pure drug Lafutidine with the polymer chitosan used in the formulation of floating microspheres. All important functional group frequencies for Lafutidine showed no significant shifts in combination spectra indicating no interaction between Lafutidine and polymers (Figure 5). It shows that there

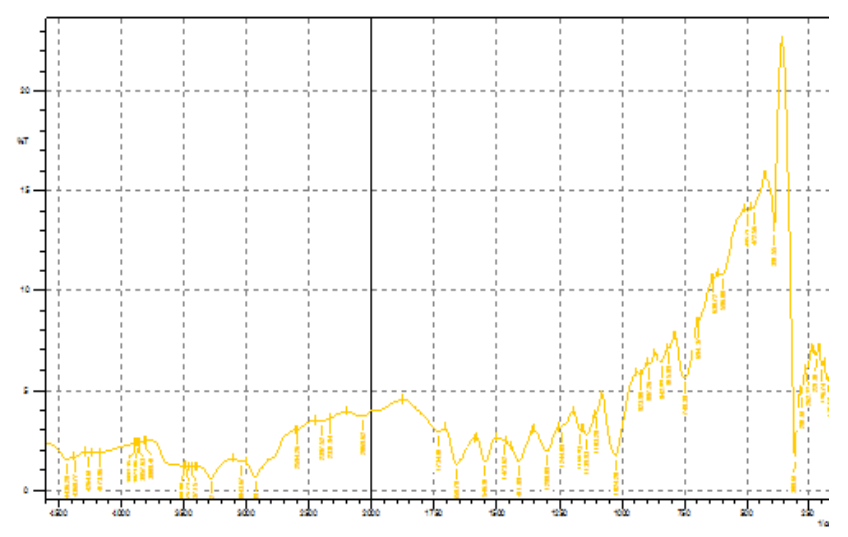

Figure 5: Fourier transform infrared (FTIR) spectroscopy of drug. was no significant change in the chemical integrity of the drug. The different functional groups are given in Table 7.

Determination of Melting Point: Capillary tube was fused from one side and then filled with the drug (Lafutidine) from another side. After that it was inserted into the melting point apparatus. Temperature was noted at which solid drug converts into liquid form by visual observation and same procedure was repeated thrice. The average range of melting point of the drug is found $102^{\circ} \mathrm{C}$. Although it is calculated by Differential Scanning Calorimetry (DSC) also as shown in Figure 6.

Differential Scanning Calorimetry (DSC):X-ray Diffraction Studies: X-ray diffraction analysis of pure Lafutidine (Figure 7) and the optimized formulation

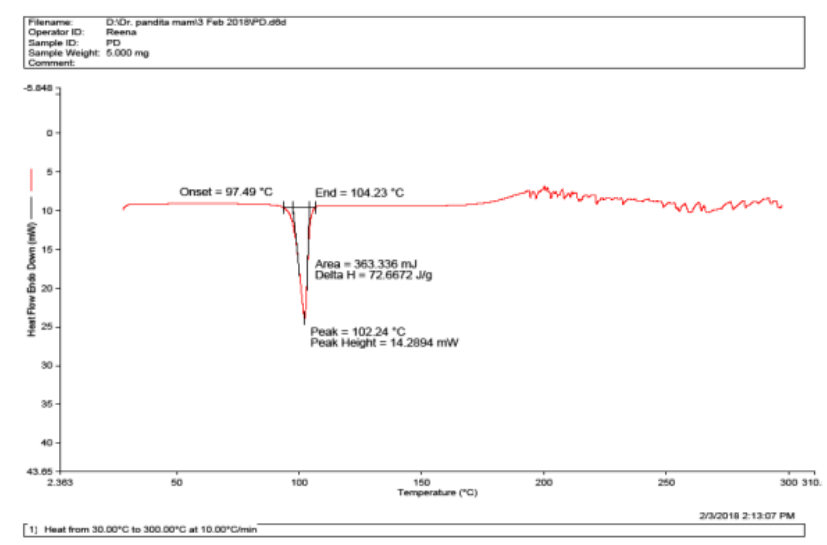

Figure 6: Differential Scanning Calorimetry (DSC).

\begin{tabular}{|c|c|c|c|c|c|}
\hline $\begin{array}{l}\text { Batch } \\
\text { No. }\end{array}$ & $\begin{array}{c}\text { Bulk Density } \\
\left(\mathrm{gm} . / \mathrm{cm}^{3}\right)\end{array}$ & $\begin{array}{c}\text { Tapped } \\
\text { Density }\left(\mathbf{g m} . / \mathrm{cm}^{3}\right)\end{array}$ & $\begin{array}{c}\text { Carr's Index } \\
\text { (\%) }\end{array}$ & $\begin{array}{c}\text { Hausner's } \\
\text { Ratio } \\
\left(H_{R}\right)\end{array}$ & $\begin{array}{l}\text { Angle of } \\
\text { repose }(\theta)\end{array}$ \\
\hline CF1 & 0.515 & 0.571 & 9.80 & 1.10 & 24.34 \\
\hline CF2 & 0.524 & 0.576 & 9.02 & 1.09 & 22.30 \\
\hline CF3 & 0.532 & 0.591 & 9.08 & 1.11 & 24.69 \\
\hline CF4 & 0.541 & 0.601 & 9.98 & 1.11 & 23.96 \\
\hline CF5 & 0.579 & 0.651 & 11.05 & 1.12 & 22.40 \\
\hline CF6 & 0.542 & 0.602 & 9.96 & 1.11 & 24.10 \\
\hline CF7 & 0.551 & 0.615 & 10.40 & 1.11 & 21.20 \\
\hline CF8 & 0.535 & 0.594 & 9.93 & 1.11 & 25.30 \\
\hline CF9 & 0.545 & 0.606 & 10.06 & 1.11 & 25.10 \\
\hline CF10 & 0.563 & 0.594 & 5.21 & 1.05 & 26.80 \\
\hline CF11 & 0.538 & 0.631 & 14.73 & 1.17 & 25.70 \\
\hline CF12 & 0.568 & 0.648 & 12.34 & 1.14 & 25.40 \\
\hline CF13 & 0.580 & 0.627 & 7.49 & 1.18 & 23.69 \\
\hline
\end{tabular}


(Figure 8) was done by X-ray powder diffracto meter (PW 3040/ 60 Xpert PRO, Panlytical, Netherlands). The X-ray diffraction patterns were recorded using $\mathrm{Cu} \mathrm{K} \alpha$ radiations $(\lambda=1.5405980 \AA)$, a current of $30 \mathrm{ma}$ and a voltage of $40 \mathrm{kv}$. The samples were analyzed over $10-402 \theta$ range with a scan step size of 0.02 and $0.50 \mathrm{~s}$ per step.

Encapsulation Efficiency: For determination of encapsulation efficiency10 $\mathrm{mg}$ microspheres were crushed and dispersed into $25 \mathrm{ml}$ phosphate buffer $(\mathrm{pH}$ 7.4). The prepared mixture was shaken for $24 \mathrm{~h}$. After 24 $\mathrm{h}$, the solution was filtered and the filtrate was analyzed for the drug content by a UV spectrophotometer at 227 $\mathrm{nm}$ after suitable dilution. The percentage encapsulation was calculated.

Buoyancy Study: The floating ability of the prepared beads were evaluated in acidic buffer ( $\mathrm{pH}$ 1.2). The

\section{Table 7: Band position and functional groups.}

\begin{tabular}{|c|c|c|}
\hline Sr.No. & Band position $\left.\mathbf{( c m}^{-1}\right)$ & $\begin{array}{c}\text { Functional Group } \\
\text { Assignment }\end{array}$ \\
\hline 1. & 3278 & -NH Stretch \\
\hline 2. & $3094-2940$ & C-H Stretch \\
\hline 3. & 1620 & C=C Stretch \\
\hline 4. & $1586-1486$ & C=O Stretch \\
\hline 5. & 1261 & N-C Bending \\
\hline 6. & $1211-1157$ & C-O Bending \\
\hline 7. & 1032 & S=O Bending \\
\hline
\end{tabular}

floating ability of the beads is directly related to the amount of gas generating agent added, in order to make the beads to float onto the surface of the media.

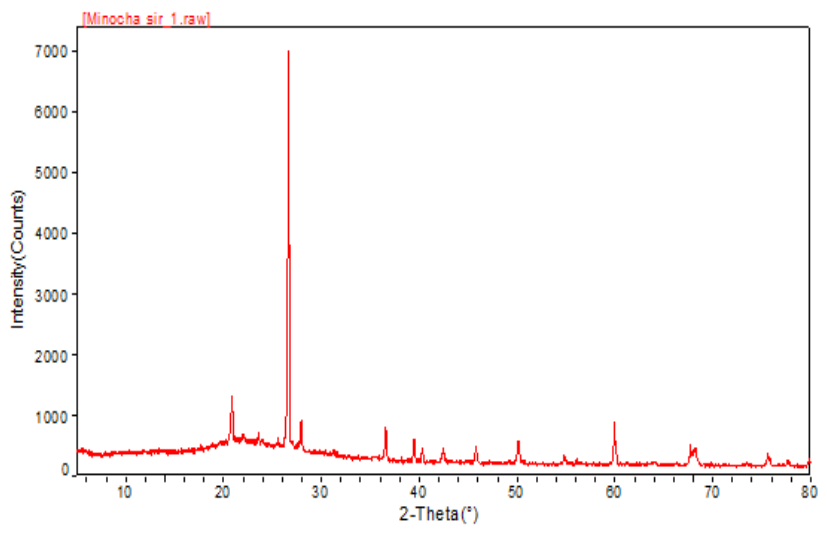

Figure 7: X-ray diffraction patterns of pure drug Lafutidine.

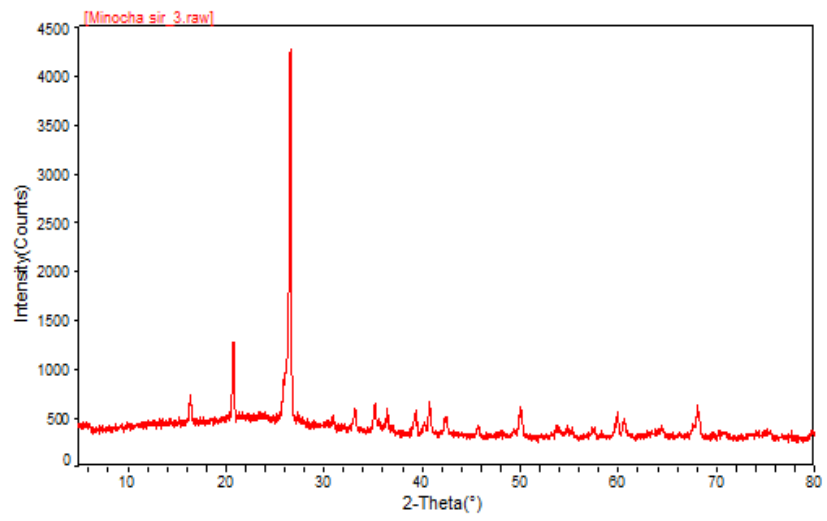

Figure 8: X-ray diffraction of drug-loaded floating microspheres.

\begin{tabular}{|c|c|c|c|c|c|}
\hline \multicolumn{5}{|c|}{ Table 8: Charaterization of microparticles. } \\
\hline \multirow{2}{*}{ Formulation code } & Shape & $\begin{array}{c}\text { Mean Particle } \\
\text { Size }\end{array}$ & Yield & Buoyancy (\%) & $\begin{array}{c}\text { Encapsulation } \\
\text { efficiency (\%) }\end{array}$ \\
\hline CF1 & Spherical & 11.62 & 72.63 & 90.28 & $91.02 \pm 3.74$ \\
\hline CF2 & Spherical & 9.47 & 68.67 & 78.33 & $73.12 \pm 2.10$ \\
\hline CF3 & Spherical & 10.23 & 76.45 & 77.56 & $85.22 \pm 1.73$ \\
\hline CF4 & Spherical & 6.43 & 79.77 & 82.33 & $88.42 \pm 1.54$ \\
\hline CF5 & Spherical & 3.43 & 89.27 & 92.55 & $95.02 \pm 3.75$ \\
\hline CF6 & Spherical & 8.56 & 86.43 & 90.32 & $84.05 \pm 6.36$ \\
\hline CF7 & Spherical & 8.29 & 76.89 & 55.67 & $79.32 \pm 2.77$ \\
\hline CF8 & Spherical & 3.78 & 81.40 & 66.67 & $79.02 \pm 1.73$ \\
\hline CF9 & Spherical & 11.89 & 81.49 & 67.98 & $86.02 \pm 2.33$ \\
\hline CF10 & Spherical & 4.87 & 79.69 & 68.65 & $79.02 \pm 1.74$ \\
\hline CF11 & Spherical & 12.66 & 80.33 & 77.55 & $84.02 \pm 3.79$ \\
\hline CF12 & Spherical & 15.38 & 82.79 & 69.99 & $72.02 \pm 2.78$ \\
\hline CF13 & Spherical & 5.88 & 81.10 & 81.55 & $83.02 \pm 1.77$ \\
\hline
\end{tabular}


Floating capacity of all the formulations ranged from $67.3 \%$ to $87 \%$ (Table 8 ). All the formulations showed a total floating time of for more than $10 \mathrm{~h}$.

In-vitro Drug Release Study: The drug release rate from different formulations (CF1- CF13) was determined using USP type II apparatus (TDT- 08L, Electro lab, Mumbai, India). Dissolution medium (SGF, $\mathrm{pH} 1.2,500 \mathrm{ml}$ ) containing $0.02 \%$ Tween 20 filled in the dissolution vessel and the temperature was maintained at $37 \pm 0.5^{\circ} \mathrm{C}$. Micro particle equivalent to $50 \mathrm{mg}$ of lafutidine were placed in the dissolution vessel and the paddle was rotated at $50 \mathrm{rpm}$. Aliquots were withdrawn every $15 \mathrm{~min}$ in the first hour and then every hour till the $4^{\text {th }} \mathrm{hr}$ followed by the 6th and $8^{\text {th }} \mathrm{hr}$ till $12 \mathrm{hr}$ and then cumulative drug release was calculated and Samples were then analyzed by a UV spectrophotometer at 228 $\mathrm{nm}$. The study was conducted in triplicate as given in Table 9.

ANOVA on percentage cumulative drug release from various formulations: Polymer decreases the drug release in formulation with increase in concentration while sodium bicarbonate increases drug release in formulation. \% CDR increases with the increase in concentration of polymer. ANOVA was applied on $\%$ CDR to study the fitting and significance of model as

\section{Table 9: Total floating time and Percentage} Cumulative Drug Releaseof Batches (CF1-CF13).

\begin{tabular}{|c|c|c|}
\hline $\begin{array}{c}\text { Batch } \\
\text { No. }\end{array}$ & Total Floating Time (hr) & $\begin{array}{c}\text { Cumulative drug } \\
\text { release }\end{array}$ \\
\hline CF1 & $>12$ & $79.42 \pm 2.13$ \\
\hline CF2 & $>11$ & $82.54 \pm 1.21$ \\
\hline CF3 & $>12$ & $89.02 \pm 2.32$ \\
\hline CF4 & $>12$ & $82.21 \pm 2.11$ \\
\hline CF5 & $>14$ & $95.41 \pm 1.57$ \\
\hline CF6 & $>13$ & $91.92 \pm 2.61$ \\
\hline CF7 & $>11$ & $84.72 \pm 1.32$ \\
\hline CF8 & $>12$ & $77.67 \pm 1.23$ \\
\hline CF9 & $>11$ & $86.67 \pm 1.87$ \\
\hline CF10 & $>12$ & $82.92 \pm 2.31$ \\
\hline CF11 & $>13$ & $82.23 \pm 2.88$ \\
\hline CF12 & & $81.71 \pm 1.76$ \\
\hline CF13 & & $86.21 \pm 2.08$ \\
\hline
\end{tabular}

given in Table 10. The model developed from multiple linear regression to estimate effect $(\mathrm{Y})$ can be presented mathematically as:

$Y=84.44-1.24 X_{1}-1.38 X_{2}+1.60 X_{1} X_{2}+2.44 X_{1}^{2}-0.44 X_{2}^{2}$ Where, $\mathrm{Y}$ is \% CDR, $\mathrm{X}$ : Drug: Chitosan Ratio, $\mathrm{X}$ : Chitosan: Gelling Agent (TPP) Ratio

F-test was carried out to compare the regression mean square with the residual mean square. The ratio $\mathrm{F}=$ 4.38 shows regression to be significant. The estimated model, therefore, may be used as response surface for the \% CDR as shown by three-dimensional surface model graph and contour plots employing Design Expert software (Version 8.0.7.1, Stat-Ease Inc., Minneapolis, $\mathrm{MN})$. The developed model can further be utilized to

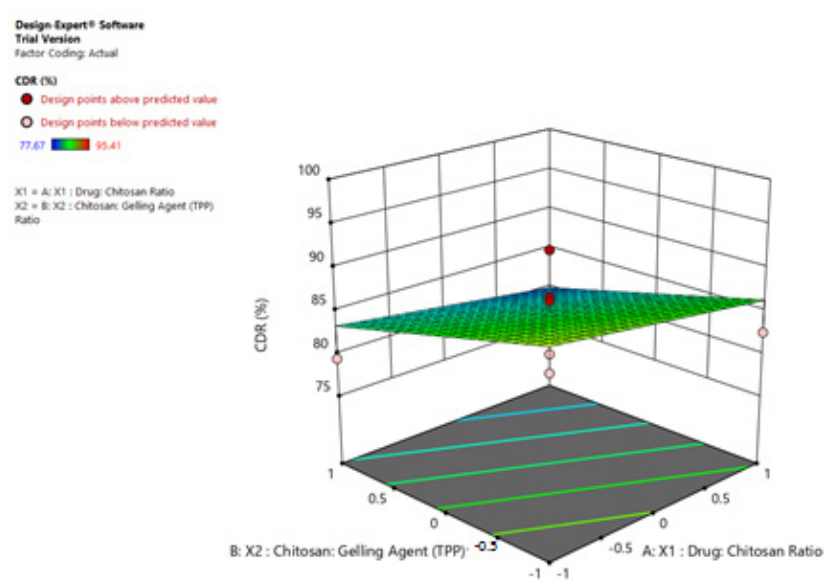

Figure 9: 3D Surface Model Graph.

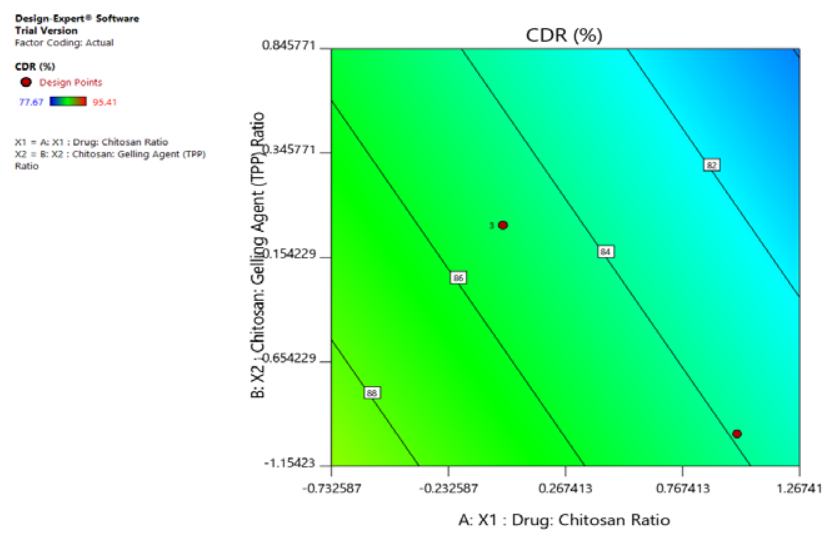

Figure 10: Contour Model Graph.

Table 10: ANOVA of the Regression (\%CDR).

\begin{tabular}{|c|c|c|c|c|c|}
\hline & $\begin{array}{c}\text { Degree of } \\
\text { freedom }\end{array}$ & $\begin{array}{c}\text { Sum of } \\
\text { squares }\end{array}$ & $\begin{array}{c}\text { Mean } \\
\text { square }\end{array}$ & F & F-significance \\
\hline Total & 18 & 193.46 & - & - & - \\
\hline Residual & 11 & 39.66 & 3.97 & - & - \\
\hline Regression & 9 & 162.80 & 16.68 & 4.29 & $0.0152^{*}$ \\
\hline
\end{tabular}




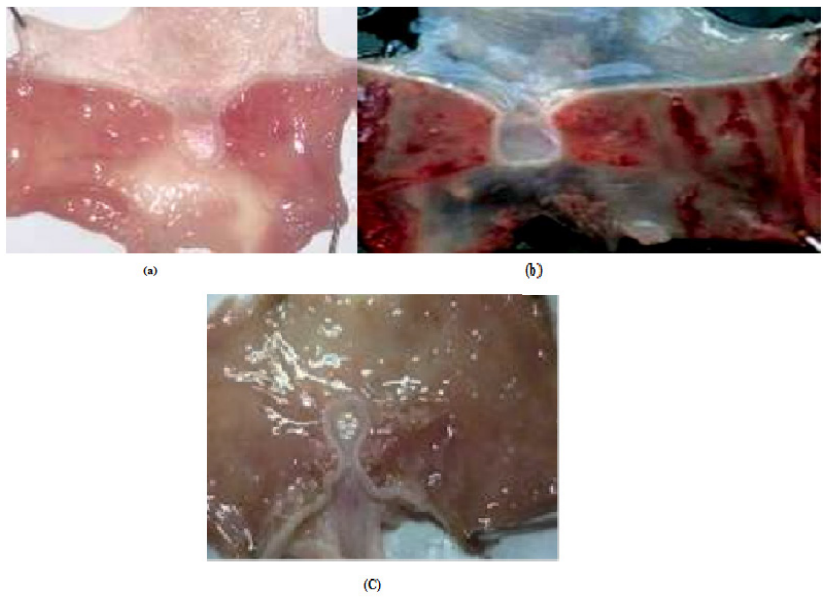

Figure 11: Evidence for the protective effect of Lafutidine microspheres in rats treated with ethanol, (a) Ulcerated control stomach (b) Optimized formulation treated stomach (c) Control group (treated with formulation without drug)

determine the desired \%CDR. Figure 9 and Figure 10 display the 3D surface and contour plot of cumulative percent of drug release as a function of formulation variables.

Release kinetics: The release data was fitted to various kinetic models in order to determine the release constant and regression coefficient. The drug release profiles for formulations (CF1 to CF13) were best is best explained by the Korsemeyer Peppas model. In Korsemeyer Peppas model if the value of $\mathrm{n}$ (slope) $=0.5$ indicates a Fickian diffusion mechanism, for $0.5<\mathrm{n}>1.0$, indicates anomalous (non-Fickian) and $n=1$ implies class 2 transport. In the present study, as per the Korsemeyer Peppas model the value of $\mathrm{n}$ (slope) was calculated 0.596 , which is a characteristic of non-Fickian drug diffusion mechanism. Thus the release profile of the optimized batch CF5, fitted best to the Korsemeyer Peppas model (0.9695). Based on the analysis parameters optimized batch was found CF5.

Antiulcer activity: In control group of animals, oral administration of absolute ethanol produced characteristic lesions in the glandular portion of rat stomach which appeared as elongated bands of thick, black and darkred lesions. In ethanol-induced ulcer model, oral administration of $95 \%$ ethanol in control group, produced characteristic lesions in stomach which emerged as elongated bands of broad red lesions. The in-vivo evaluation showed that significant protection ulcerative index $89.04 \%$ of optimized formulation of Lafutidine in comparison to control group (Figure 11).

Stability study: There was no significant change observed in the buoyancy $\%$, entrapment efficiency and in-vitro drug release as conducted at an interval of 10 days after 2 months at $40 \pm 2^{\circ} \mathrm{C}$.

\section{CONCLUSION}

Formulation CF5 showed good results with respect to the various evaluation parameters, so it was selected as the optimized formulation. The particle size increased with increase in polymer concentration. The drug entrapment efficiency was increased with increase in concentration of polymers. In-vitro buoyancy and the in-vitro drug release decreased with respect to increase in concentration of polymers. The optimized formulation showed good floating for $12 \mathrm{~h}$ in stomach of rat.

\section{ACKNOWLEDGEMENT}

The authors are highly thankful to the Late Prof.(Dr) S.K.Singh, Dept. Of Pharmaceutical Sciences, GJUS\&T, Hissar, Haryana for providing essential facilities and guidance to accomplish this research study.

\section{CONFLICT OF INTEREST}

The authors declare no conflict of interest, financial or otherwise.

\section{ABBREVIATIONS}

ANOVA: Analysis of variance; BCS: Biopharmaceutical classification system; BD: Bulk density; CDR: Cumulative drug release; CF: Chitosan formulation; cm: Centimeter; Conc.: Concentration; DSC: Differential scanning calorimetry; FDDS: Floating drug delivery system; FTIR: Fourier-transform infrared; gm: Gram; $\mu$ : Micro gram; GRDF: Gastroretentive drug formulation; HCL: Hydrochloric acid; IR: Infrared; Lab.: Laboratory; mg: Milligram; Min.: Minute; ml: Milliliter; nm: Nanometer; SEM: Scanning electron microscope; TD: Tapped density; TPP: Tripolyphosphate; USP: United states pharmacopeia; UV: Ultraviolet.

\section{REFERENCES}

1. Abraham S, Muhammed N, Peter V. Formulation and evaluation of gastroretentive drug delivery system containing combination of glipizide and metformin hydrochloride. Asian J Pharm Clin Res. 2016;9(6):235-40.

2. Kumari B, Pandey P, Dureja H. Formulation and Characterization of Gastroretentive Floating Tablets of Atorvastatin Calcium using Central Composite Design. J Pharm Res. 2017;16(3):247-56.

3. Kaustubh G, Doke O, Kasgawade P. Gastroretentive drug delivery system. JDDT. 2018;8(4):24-35.

4. Kumari B. Recent development in floating drug delivery system: A Review. AJPP. 2018;4(2):131-9.

5. Bardronnet P, Faivre V, Pugh WJ, Piffaretti JC, Falson F. Gastroretentive dosage forms: Overview and special case of Helicobacter pylori. J Control Release. 2017;111(1-2):1-18.

6. Gadad AP, Sneha SN, Panchaxari MD, Uday BB. Formulation and Evaluation of Gastroretentive Floating Microspheres of Lafutidine. J Pharm Res. 2016;50(3):S76-81 
7. Ikechukwu UR, John FDE, Ambi AA. Development and evaluation of Ritonavir hollow microballoons for floating drug delivery. Uni J Pharm Res. 2017;2(2):30-4

8. Nethaji R, Narayanan A, Palanivelu M. Formulation and Evaluation of metformin hydrochloride loaded mucoadhesive microspheres. Int J Pharma, Chem Bio Sci. 2016;6(2):124-32

9. Kashid P, Doijad R, Shete A, Sajane S, Bhagat A. Studies on Rebamipide Loaded Gastroretentive Alginate Based Mucoadhesive Beads: Formulation and in-vitro, in-vivo Evaluation. Pharma Methods. 2016;7(2):132-8.

10. Setia M, Kumar K, Teotia D. Gastro-retentive floating beads a new trend of drug delivery system. JDDT. 2018;8(3):169-80.

11. Krutika S, Mitali P, Jiten PM. Formulation, optimization, characterization and in vivo anti-ulcer activity of esomeprazole magnesium trihydrate gastro resistant microspheres. Int J Pharm Pharm Sci. 2017;9(1):273-82.
12. Laila HE, Aya RA, Ahmed A, Ashmawy E, Nadia MM. Preparation and evaluation of metronidazole sustained release floating tablets. Int $\mathrm{J}$ Pharm Pharm Sci. 2014:6(9):198-204

13. Ayre A, Dand N, Lalitha KG. Gastro-retentive Floating and Mucoadhesive Drug Delivery Systems- Insights and Current Applications. IOSR J Pharm Bio Sci. 2016;11(3):89-96

14. Kakar S, Singh RS. Gastroretentive drug delivery systems: A review. African J Pharma and Pharmacology. 2015;9(12):405-17.

15. Jaya S, Srilaxmi G. Formulation and in-vitro characterization of ambroxolhydrochlotide sustained release matrix tablets. Int J Pharm Sci Res. 2019;10:1000-6

\section{PICTORIAL ABSTRACT}

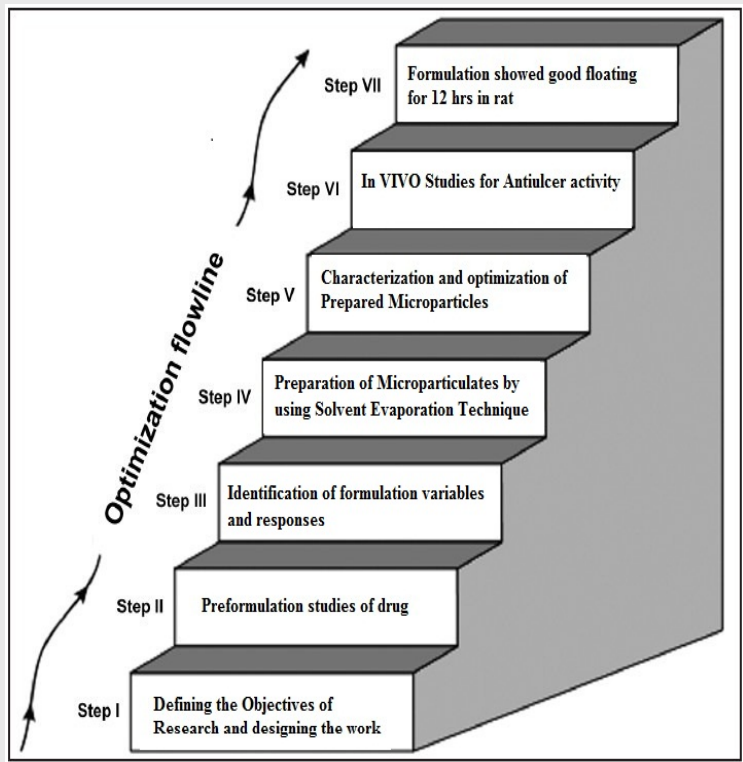

\section{About Authors}

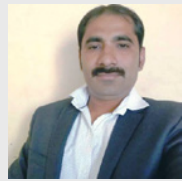

Sunil Kumar did his B.Pharmacy in 2006, LSCP, SPSA, M.Pharmacy (Pharmaceutics) in 2008 from Annamalai University, (T.N), Sumbmitting Doctorial Research work in Pharmaceutics (Ph.D), Uttarkhand Technical University, Dehradun. Presently working as Assistant Prof. or Head, Department of Pharmaceutics, Vanish Institute of Pharmaceutical Education and Research, Rohtak (HR). He is having more than 11 years teaching Experience. He guided 10 Research Project at PG level. He is having more than 15 publications in national and international journal. $\mathrm{He}$ attended more than 25 national and international conference, 02 FDP and Presented papers. $\mathrm{He}$ is having life membership of IPGA, IPA, HSPC etc. He had successfully organised the CPE Programm of Harjana state Pharmacy council as a coordinater in 2014 and 2019 at Rohtak.

\section{SUMMARY}

The Gastroretentive Micro particulate system had formulated using central composite design to stay in the stomach for prolonged time and worn for gastroretentive drug delivery. Gastroretentive Microspheres were prepared by using Emulsion Solvent Evaporation technique. Micro particulate system were assessed for micro meritic study, percentage yield, drug entrapment efficiency, in-vitro buoyancy, surface morphology, in-vitro drug release, invivo floating study and stability studies. The micro meritic parameters of floating microspheres were found to be within the acceptable limits. The particle size of microspheres was found to be in the range $3.43-15.38 \mu \mathrm{m}$. The entrapment efficiency was found to be in the range of $72.02-95.02 \%$. The floating microspheres were spherical in shape with distinct pores, slightly rough surface when observed under scanning electron microscopy. The percentage yield was found to be in the range of $68-89 \%$. The in vitro buoyancy was found to be in the range of $55.67-92.55 \%$ and a total buoyancy time of more than $10 \mathrm{~h}$. The in vitro dissolution studies showed a cumulative $\%$ release in the range of 77.67-95.41\%. All the formulations followed Korsemeyer- Peppas kinetics indicating drug release by non-fickian release mechanism. The stability studies showed that floating microspheres were stable at $40 \pm 2{ }^{\circ} \mathrm{C}$. The optimized formulation showed good floating for $8 \mathrm{~h}$ in stomach of rat. The formulations were able to treat the alcohol induced ulcer.

Cite this article: Kumar S, Goyal N. Formulation and Characterization of Chitosan Microparticulate System Using Central Composite Design for the Drug: Lafutidine. Indian J of Pharmaceutical Education and Research. $2021 ; 55(2): 354-62$. 